\title{
CREATING A FOOD MENU APPLICATION FOR MENDEL UNIVERSITY IN BRNO
}

\author{
Petr Tykal ${ }^{1}$, Diana Brnovik¹, Jaromír Landa ${ }^{1}$ \\ ${ }^{1}$ Department of Informatics, Faculty of Business and Economics, Mendel University in Brno, Zemědělská 1, \\ 61300 Brno, Czech Republic
}

Link to this article: https://doi.org/10.11118/actaun202068010275

Received: 3. 6. 2019, Accepted: 2. 12. 2019

To cite this article: TYKAL PETR, BRNOVIK DIANA, LANDA JAROMÍR. 2020. Creating a Food Menu Application for Mendel University in Brno. Acta Universitatis Agriculturae et Silviculturae Mendelianae Brunensis, 68(1): 275-280.

\begin{abstract}
The presented paper describes the creation of a mobile application module for showing a current menu at Mendel University cafeterias. Nowadays, the students and the university staff have the menu accessible through a static webpage. The presented solution serves as a dynamic presentation of the current menu for all Mendel University in Brno cafeterias. Most cafeteria menu applications use the REST architectures for the server backend. The contribution of the paper is in usage of the Google Firebase Realtime database as a server backend. Unlike in traditional REST architecture, the data e.g. the food rating is instantaneously changed and the users have an up to date information. Part of the presented solution is also a mobile application module for both Android and iOS where university students and staff can see the current cafeterias menus.
\end{abstract}

Keywords: Android, iOS, food, canteen, mobile application, Firebase

\section{INTRODUCTION}

Almost any university in the world has some sort of food court to provide meals to their students and staff. This gives a need to show the food menu for each day, usually for each day of the week. Mendel University in Brno has a total of 7 cafeterias, including a small pizzeria. Some cafeterias are located in the university campus in Brno, others are located near the dormitories. Nowadays, the menu is presented in a form of a static webpage, which shows a menu for the current date and next 5 working days. However, the web page is just a single page with no possibility of any added content except the menu.

This article describes the creation of an application module for Android and iOS platforms. The purpose of this module is to show a current cafeteria menu to the students and staff of Mendel University in Brno. The module will allow the showing of images associated with particular meals, to rate the meals and to customize the content shown to the users. The module is a part of a larger application developed by students and staff at Faculty of Business and Economics called My MENDELU1'. Most common server backend choice for this type application is REST architecture (Albertengo et al., 2019). However, the architecture does not allow real-time refresh of the data. The contribution of the paper is in usage of Firebase real-time database for such application. The Firebase real-time database allows to refresh the cafeteria information in realtime.

1 https://play.google.com/store/apps/details?id=cz.mendelu.mymendelu\&hl=en, https://apps.apple.com/us/app/mymendelu/id1467807496 


\section{MATERIALS AND METHODS}

Mobile applications containing menu information can be found both in Czech Republic and abroad. Many universities have their own mobile application for food courts, such as Charles University. They use the MobilKredit ${ }^{2}$ application. One example of a food count application abroad can be found in Switzerland. The application name is Zuri Mensa (Schneider, 2019). This application is available on App Store and Google Play. The application is aimed at providing menus of the university's canteens for students of University of Zurich (UZH), Swiss Federal Institute of Technology Zurich (ETHZ) and Zurich University of Teacher Education (PHZH). Pros of the application are clean GUI design, simple navigation between menus, list of allergens (if available) and the map of certain canteens. The application does not have many cons with which users could relate based on that the positive reactions and recommendations on online stores. The application contains two different language settings which are English and German.

Another example can be found in Opera Universitaria of Trento (Trilogis srl, 2018). The application, UniMea is also aimed at providing useful canteens' information and its available menus. The application differs from other applications of the same type by offering five HD webcams streams which show the real-time queue inside canteens. The application is available on App Store and Google Play in two languages, English and Italian. SIGFOOD mobile application aims to provide food information for Techfak-Mensa at University Erlangen in Germany. The users of the application can easily view images of served meals. The application also contains comment sections for sharing reviews based on users' satisfaction with the served meal. The application is available to download on App Store and Google Play.

Any application is only an extension of the cafeteria services. There are several researches concerning the cafeteria service, the quality of food and the tracking of students in cafeteria. One example can be found in El-Said and Fathy (2015). They are accessing the student's satisfaction with cafeteria services. The results show, that the quality of food and beverages has the greatest impact on student satisfaction. The lowest impact on student satisfaction has the quality of service. Tang, Zhang and Xie (2019) try to track and model the pedestrian flow in university canteen. They can provide the cafeteria management suggestions how to optimize the flow of students in cafeteria to enhance the cafeteria service efficiency and safety.

When choosing the architecture for a server to communicate with mobile application there are several options. Most commonly, the first choice is
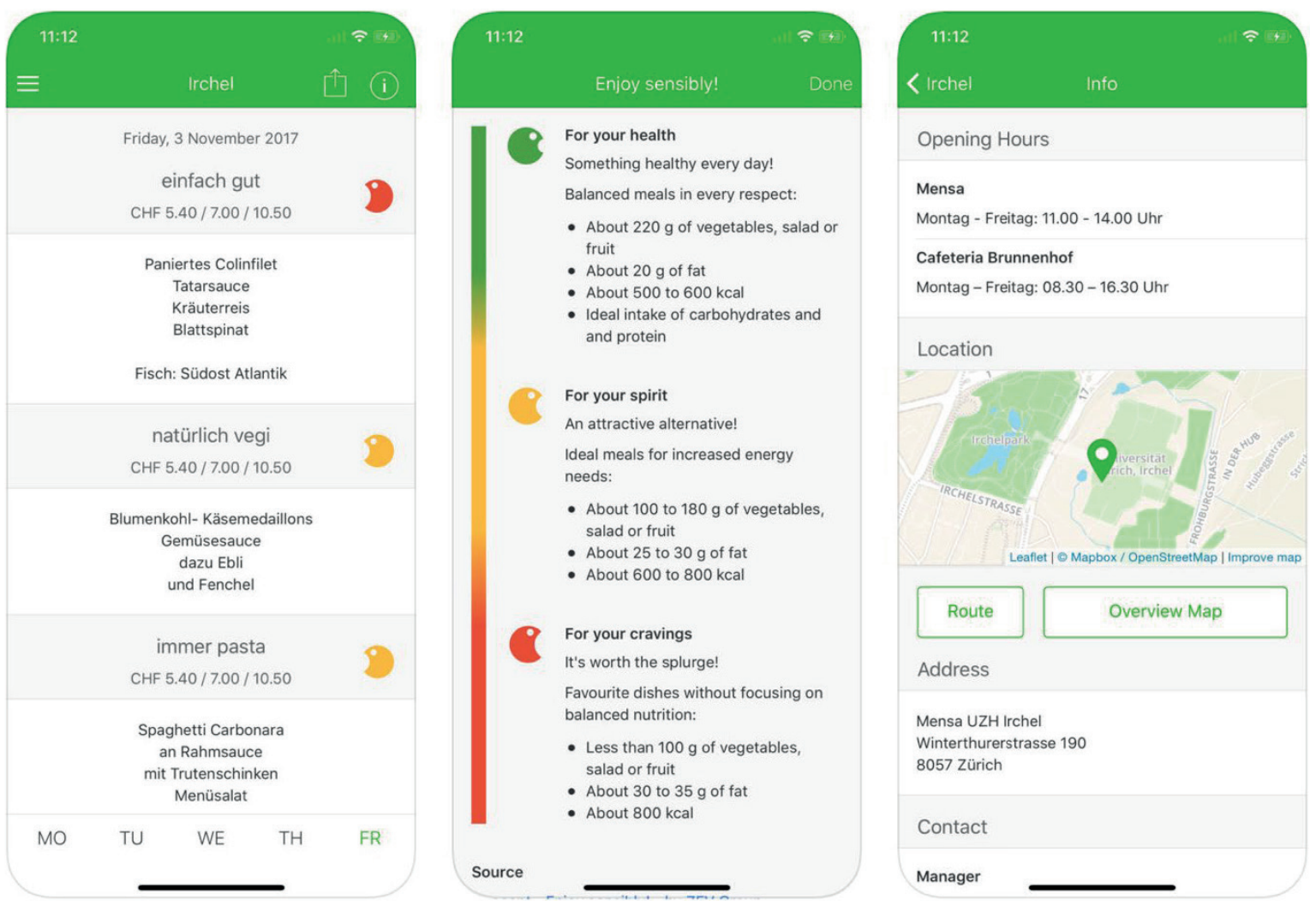

1: Screens from a mobile application "Zuri Mensa"

2 https://play.google.com/store/apps/details?id=anete.droid. mobilkredit 
a REST (Pautasso, 2014; Albertengo et al., 2019). Even though the architecture has many advantages we can also found disadvantages. One of the disadvantages is the need to perfectly synchronize the device and server state at any given moment (Albertengo et al., 2019). Nowadays, the REST is the most popular option as a server backend architecture in connection with mobile application. However, due to the real time nature of our data, it was necessary to find alternative service. Probably the most common alternative to standard REST API architecture is Google Firebase $^{3}$. Firebase is a web and mobile development platform. The usage of Firebase can be found in many applications. Alamgir, Jahan, Aktar et al. (2019) uses Firebase to send bus locations and display them in real time to users. Another such usage of Google Firebase can be found in Jisha, Mathews, Kini et al. (2018) or Jain, Garg, Bhosle et al. (2018). The Firebase is traditionally used in applications where there is a need for fast exchange and refresh of data. Naparaju, Pranavi and Kalyani (2019) uses Firebase platform to develop an intuitive advertisements. Yeh, Chen (2018) uses Firebase for Indoor Guidance system for visual impaired people. Chasapis, Mitropoulos and Douligeris (2019) discuss the advantages of using Firebase. Among many, it is the possibility to add quickly more functions to the application and the possibility to add cloud functions without the need for custom backend server.

\section{Solution}

Nowadays, the cafeteria menu of Mendel University in Brno is available only at the university website ${ }^{4}$. The university website shows a list of cafeterias and a menu for a current day. The webpage also shows the basic information about each cafeteria, such as address and opening hours. The website is in Czech and English languages. The disadvantage of the website is just a static presentation of the menu. For example, the page does not contain any meal images. In 2014, the mobile application "Jídelníček MENDELU" was available to the students and staff (Grenar, 2018). This application showed the menu of Mendel University in Brno canteens and allowed its user to share their satisfaction with the served meal by voting. This application was unofficial, and it was created by a university student. Currently, the application is no longer available on App Store or Google Play.

The proposed solution consists of two parts. The first part is a server backend containing all the data. The second part is a mobile application module for showing the cafeteria menu. The module was developed for both platforms, Android and iOs.

\section{Server Backend}

As a server backend, the Firebase was chosen. Firebase provides two key functionalities for the module, real-time database, and the storage. The reason for choosing Firebase was a real time nature of the data. The information about meals can change during the day and we wanted to be able to notify the user about the change without a need to refresh the user interface all the time. The storage is used to store the food images.

The Firebase server is filled with current menus every day. The current food court menus are downloaded from the food cafeterias information system in a XML file format. After the download, they are parsed and send to the Firebase to be deployed to the mobile applications. The update of the menu is done twice a day to insure the up to date information.

The data in the real-time database are hierarchically structured. The tree hierarchy is divided into 4 parts. The first part is a complete list of allergens. If we need to change the information about the allergen, it can be done in one place. The second part is a list of meal types. The cafeteria can serve up to 6 different types of meals. These types are defined in this part of the tree structure. The third part are images. Any meal can be associated with a large amount of images. For each meal, we store a list of images. The images are stored separately from the meals to make the information about the meal more compact. For each image, we store the name in the Firebase storage and the date it was uploaded. The last and most important part is a list of canteens. For each canteen we store its name, location, number of seats, opening hours and menu for the next 5 working days. The example structure can be seen in Appendix 1. For each day we store its date and a list of menu items for the day. For each menu item, we store allergens, the name, type, price, and the rating. The reason for storing the data as a tree structures is to allow users to have the cafeteria menu even in offline mode without the internet connection.

\section{User Interface}

The main idea behind the user interface was to have a unified user interface design respecting each platforms rules and guidelines. The key part of the module is the main screen showing a list of meals for a day. Because the Mendel University in Brno has many cafeterias, the user can switch between them to see what the menu is in each of them. For the android, the user can see the menu for all the cafeterias, however for the iOS, only 3 can be visible at one time. The number of cafeterias can be changed in settings (see Fig. 3). For both platforms,

3 https://firebase.google.com/

4 http://ipm.mendelu.cz/menu 

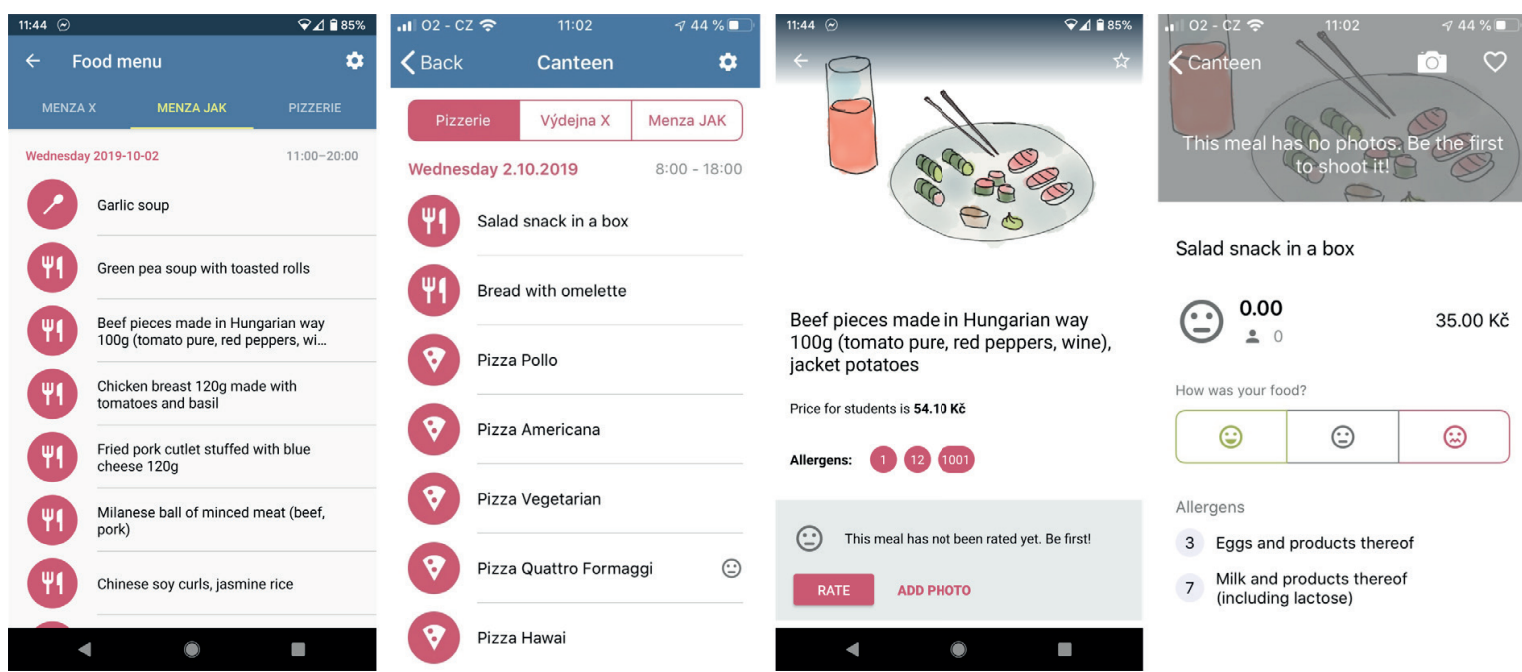
Beef pieces made in Hungarian way
$100 \mathrm{~g}$ (tomato pure, red peppers, wine) jacket potatoes

○) $0.00 \quad 35.00 \mathrm{Kč}$
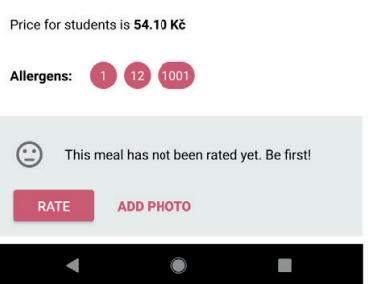

\begin{tabular}{|c|c|c|}
\hline ;) & $\odot$ & (2) \\
\hline
\end{tabular}

Allergens

3 Eggs and products thereof

7 Milk and products thereof

2: The screens from the described module. From left: The list of meals: Android and iOS, the screen showing the meal detail information: Android and iOS.
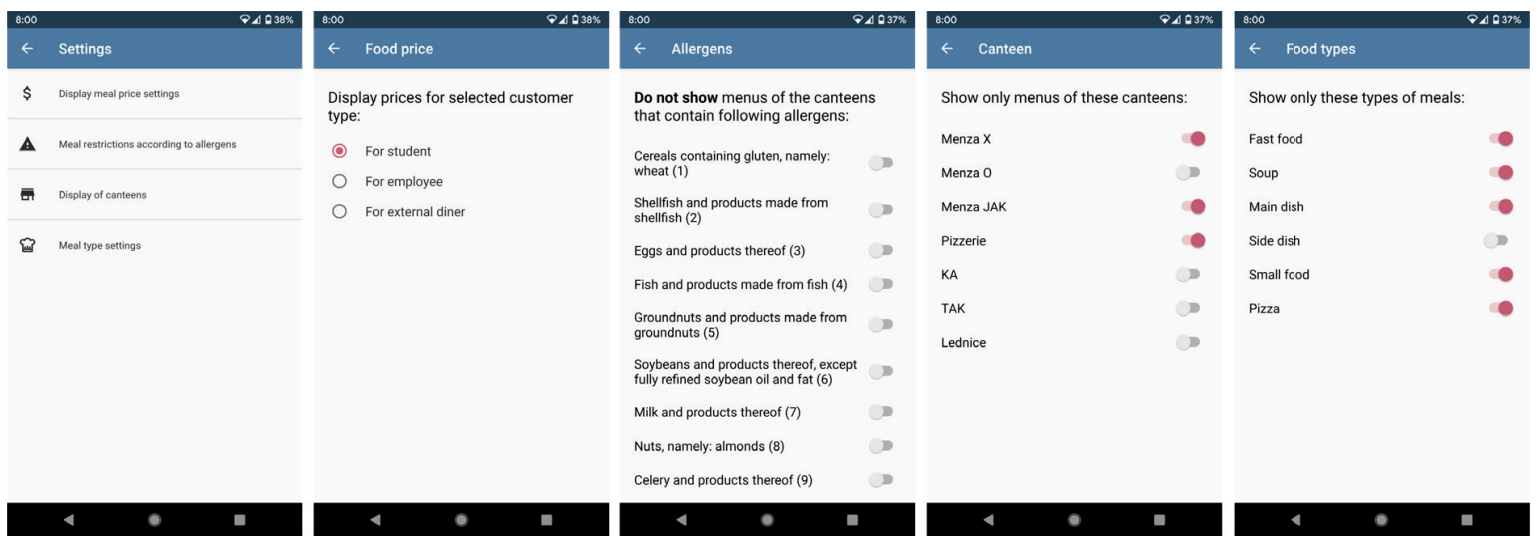

3: The settings for Android platform. From left: The main settings screen, price settings, allergens settings, food courts settings and food type settings.

the initial number of cafeterias is set to 3 . The main screen can be seen in Fig. 3. Because the Firebase real-time database is used as a storage, the main screen updates itself whenever the data stored in Firebase changes e.g. the food ranting is changed by the other users.

Taping on the list item at the main screen will lead the user to the detail information about the meal. The detail information (Fig. 2) contains the name of the meal, the price, the list of allergens and many more. The price can be of 3 different types (for students, staff or external diners).

The detail page also contains the images associated with the meal. By tapping on the image, the full image preview is opened. Only the first image is downloaded from the storage. Before the image is downloaded, a full list of images it retrieved from Firebase. Only when the users swipe through images they are downloaded from Firebase storage.
An interesting part of the detail information is the possibility to mark the meal as favorite. This information is also shown next to the name of the meal in the main list.

Important part of the user interface are Settings. The user can change 4 different settings. The first setting is price setting. User can choose what prices will be shown. As mentioned above, there are three different types of prices, for students, staff or external diner. The next setting is to limit the meals based on allergens. The user can filter the meals based on allergens. Only a meal without specific allergens will be shown. The third and very important setting is the ability to change the number of cafeterias shown on main page. The last is the setting to set what types of meals (soup, main course ...) will be shown in a main list. The settings for Android are in Fig. 3. 


\section{DISCUSSION AND CONCLUSION}

This article describes the creation of a mobile application module for showing the cafeteria menus at Mendel University in Brno. The module is a self-sufficient part of a larger application for university students and staff called My MENDELU. The module shows the day menu for all canteens operated by the university. The module was created for both Android and iOS. As a server backend for storing the data, we have chosen the Firebase real-time database and storage. The main advantage of choosing the Firebase as the server backend is the update of data in real time. The users can see the change in data instantaneously and do not have to refresh the screen to see the change. During the implementation, we found several challenges. The first one was the size of images. With each meal, we show many images captured by the users. However, in most cases the size of the image is too large. This is a biggest disadvantage of storing images on Firebase storage, because the size of the storage is limited. For this reason, we decided to apply compression and size reduction to images. The images also bring another challenge. Right now, any user can send an unlimited amount of images. In the future, we will need to apply an image approval system.

On top of the ability to see a daily menu, the students and staff have a possibility to rate the meal. The meal rating was an interesting challenge. We decided to use a 3 values rating system using a smiley faces. Only longer testing will reveal if users will embrace this form of meal rating.

The users can also mark the meal as their favorite. The module also provides a large number of settings from limiting the number of canteens shown to filtering out meal with specific allergens.

As can be seen in the previous chapter, the database scheme is prepared for future development. One information we hope to store and show to the users in a future is a food availability which will be obtained either from a cafeteria staff or from the application users. Other information we hope to show in future are queues in cafeterias. We started experimenting with a possibility to track users in cafeterias using iBeacons.

The application module and the cafeterias menu are in both Czech and English.

Acknowledgements

This work was supported by grant IGA PEF_TP_2019006 (Web services for "Smart faculty”).

\section{REFERENCES}

ALAMGIR, M., JAHAN, I., AKTAR, N. et al. 2019. Chittagong university teachers' bus tracking system using smartphone application. In: $4^{\text {th }}$ International Conference on Electrical Engineering and Information and Communication. 13-15 Sept. 2018, Dhaka, Bangladesh, Bangladesh. IEEE.

ALBERTENGO, G. et al. 2019. On the performance of web services, google cloud messaging and firebase cloud messaging. Digital Communications and Networks, In Press.

EL-SAID O. A. and FATHY, E. A. 2015. Assessing university students' satisfaction with on-campus cafeteria services. Tourism Management Perspectives, 16: 318-324.

GRENAR, D. 2019 Jídelníček MENDELU. TapFame. [Online]. Available at: https://tapfame.com/ app/705145435/jidelnicek-mendelu/\#_ [Accessed: 2019 January 13].

JAIN, S., GARG, R., BHOSLE, V. et al. 2018. Smart university-student information management system. In: Proceedings of the 2017 International Conference on Smart Technology for Smart Nation, SmartTechCon 2017, pp. 1183-1188.

JISHA, R. C., MATHEWS, M. P., KINI, S. P. et al. 2018. An android application for school bus tracking and student monitoring system. In: IEEE International Conference on Computational Intelligence and Computing Research, ICCIC 2018. 13-15 Dec. 2018, Madurai, India, India. IEEE.

NARAPARAJU, S., PRANAVI, J. and KALYANI, N. 2019. Smart Poster for Tourism Promotion Through NFC Technology. In: Integrated Intelligent Computing, Communication and Security. Springer, pp. 507-519.

PAUTASSO, C., WILDE, E. and ALARCON, R. 2014. REST: Advanced Research Topics and Practical Applications. Springer-Verlag New York.

SCHNEIDER, L. 2019 Züri Mensa on the App Store. iTunes. [Online]. Cupertino, Kalifornia, USA: Apple Inc. Available at: https://itunes.apple.com/us/app/z\%C3\%BCri-mensa/id568945864?preserveScroll Position=true\#?platform=iphone [Accessed: 2019, January 13].

TANG, T., ZHANG, B. and XIE, C. 2019. Modeling and simulation of pedestrian flow in university canteen. Simulation Modelling Practice and Theory, 95: 96-111.

TRILOGIS SRL. 2018 UniMeal - UNITN Trento on the App Store. iTunes. [Online]. Cupertino, Kalifornia, USA: Apple Inc. Available at: https://itunes.apple.com/us/app/unimeal-unitn-trento/ id1227298984? mt=8. [Accessed: 2019 January 13]. 
YEH, Y. and CHEN, H. 2018. Indoor Guidance System for the Visual Impaired Using Beacon Sensors. In: Computers Helping People with Special Needs. 16 ${ }^{\text {th }}$ International Conference, ICCHP 2018. Linz, Austria, July 11-13, 2018. Part II, pp. 51-54.

\section{APPENDIX}

Appendix A: The example of the JSON file structure used to store menu information

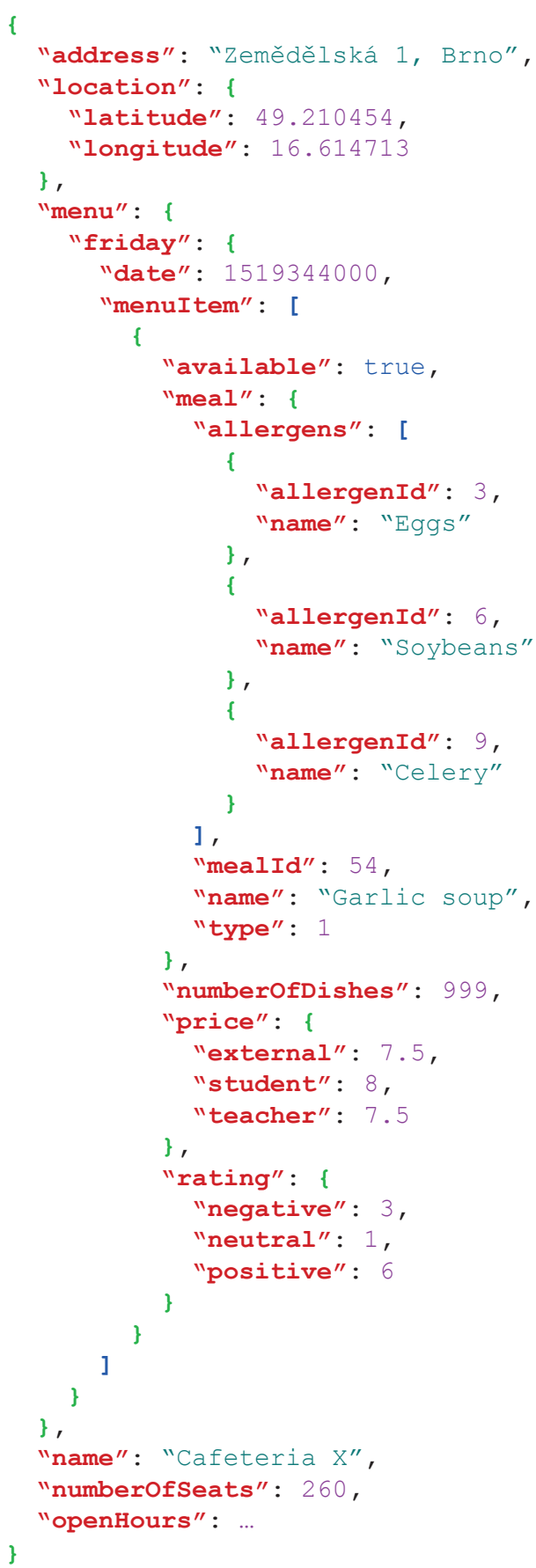

Contact information

Petr Tykal: xtykal@node.mendelu.cz

Diana Brnovik: xbrnovik@node.mendelu.cz

Jaromír Landa: jaromir.landa@mendelu.cz 